\title{
Evaluation of nicotine sensor based on copper nanoparticles and carbon nanotubes
}

\author{
Zohreh Goodarzi • Morteza Maghrebi - Alireza Fakhari Zavareh • \\ Zahra-Beagom Mokhtari-Hosseini • Bahman Ebrahimi-hoseinzadeh • \\ Ashrafasadat Hatamian Zarmi • Mohammad Barshan-tashnizi
}

Received: 27 December 2014/ Accepted: 26 February 2015/Published online: 18 April 2015

(C) The Author(s) 2015. This article is published with open access at Springerlink.com

\begin{abstract}
An electrochemical sensor was prepared to detect nicotine by depositing copper nanoparticles (Cu NPs) on the surface of a glassy carbon electrode (GCE) modified with multi-walled carbon nanotubes (MWNTs). The modified electrode was characterized by scanning electron microscopy and cyclic voltammetry. The novel-modified sensor exhibited effective electrocatalytic activities toward anodic oxidation of nicotine. Calibration plot showed two linear regions with different sensitivity, $1.121\left(r^{2}=0.982\right)$ in the range from $1 \times 10^{-6}$ to $9 \times 10^{-5} \mathrm{M}$ and 0.164 $\left(r^{2}=0.982\right)$ from $1 \times 10^{-4} \mathrm{M}$ up to $1 \times 10^{-3} \mathrm{M}$. The detection limit was $1 \mu \mathrm{M}$. For six parallel detections of $1 \mathrm{mM}$ nicotine, the relative standard deviation was $5.68 \%$, suggesting that the film-modified electrode had good reproducibility. Experimental parameters affecting the sensor response such as $\mathrm{pH}$, modifier concentration and electrodeposition scan rate were found to be optimum at 7.0, $2 \mathrm{mg} \mathrm{mL}^{-1}$ and $80 \mathrm{mV} \mathrm{s}^{-1}$, respectively.
\end{abstract}

Z. Goodarzi · M. Maghrebi

Department of Chemical Engineering, Faculty of Engineering,

Ferdowsi University of Mashhad, Mashhad, Iran

\section{A. F. Zavareh}

Department of Chemistry, Faculty of Science, Shahid Beheshti

University, Tehran, Iran

\section{Z.-B. Mokhtari-Hosseini}

Chemical Engineering Group, Faculty of Petroleum and Petrochemical Engineering, Hakim Sabzevari University, Sabzevar, Iran

B. Ebrahimi-hoseinzadeh $(\bowtie) \cdot$ A. H. Zarmi

M. Barshan-tashnizi

Department of Life Sciences Engineering, Faculty of New

Sciences and Technologies, University of Tehran, Tehran, Iran e-mail: bahman.ebrahimi@ut.ac.ir
Keywords Copper nanoparticles - Cyclic voltammetry · Multi-walled carbon nanotube $\cdot$ Nano-biosensor $\cdot$ Nicotine

\section{Introduction}

Five million people annually die due to adverse effects of smoking, a common risk factor for cardiovascular diseases $[1,2]$. As a main component of tobacco smoke, nicotine has been the topic of many researches. Several techniques have been employed to identify nicotine, such as chromatography [1-3], spectrophotometry [4], and Raman spectroscopy [5]. These techniques are generally complex and include time-consuming steps of preparation and preconcentration [6]. In contrast, electrochemical methods are simple, inexpensive, and reliable approaches for the detection of nicotine [6-9]. However, they have some limitations, such as slow oxidation/reduction and low sensitivity [10-12]. There are two ways to improve the sensitivity of the sensing electrode, namely changing the base electrode material $[8,13,14]$ or using the surface modifiers $[15,16]$. Despite the simplicity of the former, the corresponding peak potential of nicotine oxidation through this method is much higher than the similar previous findings with other methods [8]. In contrast, the surface modifiers are more affordable and comprise a collection of diverse options. So far as the authors are concerned, some surface modifiers, such as MWNTs [7] and carbon nanotube clusters [8] have been employed in nicotine detection; for instance, MWNTs/GCE have been used to improve detection limit of nicotine to 9.3 [7] and $2.0 \mu \mathrm{M}$ [8] using clusters of carbon nanotube-modified GCE. To further enhance the electrocatalytic activity for the oxidation of nicotine in the present research, the researchers modified GCE by MWNTs and copper nanoparticles $\mathrm{Cu}$ 
NPs). MWNTs could significantly improve the sensitivity when they were combined with $\mathrm{Cu}$ NPs. This improvement facilitates the electron transfer in electrochemical reactions. The modified electrodes with MWNTs and Cu NPs have already been used to identify carbohydrates [17], glucose, and hydrogen peroxide [18]. It should be noted that, $\mathrm{Cu}$ NPs are cheaper and more available than other nano-particulate modifiers such as gold [19-22] and platinum [23-26] nanoparticles. Besides, regarding the combination of $\mathrm{Cu}$ NPs and MWNTs in this study, the researchers directly used cyclic voltammetry (CV) for the deposition of $\mathrm{Cu}$ NPs. This method is easier and simpler than the conventional methods such as chronoamperometry and potential step [23]. Recently, using this method to deposit Pt nano-flowers on single-walled carbon nanotube membrane, Su et. al [26] achieved a very good sensitivity $\left(7.27 \mu \mathrm{A} \mathrm{cm}^{-2} \mathrm{mM}^{-1}\right)$.

\section{Materials and Methods}

\section{Reagent}

MWNTs were purchased from the Research Institute of Petroleum Industry (RIPI) of Iran. Nicotine and all the other chemicals were purchased from Merck Company. The main solvent was distilled water, which was prepared in the laboratory. $\mathrm{N}, \mathrm{N}$ dimethylformamide (DMF) with purity of (GC) $>99.8 \%$ was also purchased from Merck. Alumina slurry $(0.05 \mu \mathrm{m})$ was used for polishing and nitrogen $(99.99 \%)$ was used for drying.

\section{Instrumentation}

Cyclic voltammetry was carried out with electrochemical analyzer ( $\mu$ Autolab-Type III, made in Netherlands). The three-electrode configuration consisted of a modified glassy carbon electrode $(1.8 \mathrm{~mm}$ diameter) as the working electrode, $\mathrm{Pt}$ wire as the auxiliary electrode, and $\mathrm{Ag} / \mathrm{AgCl}$ (3 M) as the reference electrode. Sonication was carried out with ultrasound (WiseClean, made in Korea).

\section{Preparation of MWNTs}

Before using MWNTs for modifying the surface, they were functionalized with a carboxylic acid group. For this purpose, MWNTs were refluxed in a mixture of concentrated $\mathrm{HNO}_{3}$ and $\mathrm{H}_{2} \mathrm{SO}_{4}(1: 3 \mathrm{v} / \mathrm{v})$ for $24 \mathrm{~h}$. Then, they were washed several times with distilled water until $\mathrm{pH}=7.0$ was achieved.

\section{Preparation of MWNTs/GCE}

To avoid any contamination, the researchers carefully polished glassy carbon electrode (GCE) with $5 \mu \mathrm{m}$ alumina slurry and sonicated it in ethanol. After rinsing by doubledistilled water, it was coated by $10 \mu \mathrm{L}$ of MWNTs suspension and dried at room temperature. To prepare various concentrations of MWNTs suspension, the researchers sonicated MWNTs in dimethylformamide (DMF) for $30 \mathrm{~min}$ to be quite homogeneous.

\section{Preparation of NPs-Cu/MWNTs/GCE}

$\mathrm{Cu}$ NPs were electrodeposited on MWNTs/GCE by $\mathrm{CV}$ in the range of -0.75 to $+0.3 \mathrm{~V}$. It was done at a scan rate of $100 \mathrm{mVs}^{-1}$ for 20 cycles in $0.1 \mathrm{~mol} \mathrm{~L}^{-1} \mathrm{KCl}$ solution containing $1.75 \mu \mathrm{mol} \mathrm{L}{ }^{-1} \mathrm{CuCl}_{2}$. Then, the electrode was dried under $\mathrm{N}_{2}$ atmosphere.

\section{Result and discussion}

\section{Electrochemical behavior of nicotine}

Voltammograms of GCE, MWNTs-GCE, and Cu NPs/ MWNTs/GCE were recorded at the scan rate of $50 \mathrm{mVs}^{-1}$ in $0.1 \mathrm{M}$ phosphate buffer solution $(\mathrm{pH}=7.0)$ in the presence of $0.001 \mathrm{M}$ nicotine (see Fig. 1a-c). Nicotine exhibited an irreversible oxidative peak at about $+0.75 \mathrm{~V}$, on these electrodes, without any reduction peak.

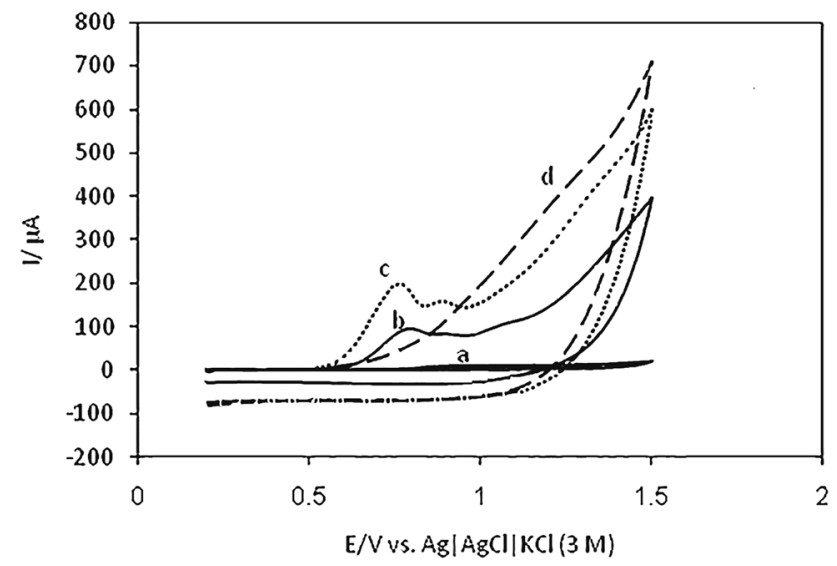

Fig. 1 Cyclic voltammograms of GCE (a), MWNTs/GCE $(b)$, and NPs-Cu/MWNTs/GCE $(c, d)$ in $0.1 \mathrm{M}$ phosphate buffer $(\mathrm{pH} 7.0)$ in the presence (solid and dotted lines) and absence (broken line) of $0.001 \mathrm{M}$ nicotine with a scan rate of $50 \mathrm{mV} \mathrm{s}^{-1}$ 
Oxidation potential of nicotine in this study was much lower than the corresponding values for boron-doped diamond electrodes $(+1.3 \mathrm{~V}$ vs. $\mathrm{Ag} / \mathrm{AgCl})[8]$, and the pencil graphite electrode $(+0.91 \mathrm{~V}$ vs. $\mathrm{Ag} / \mathrm{AgCl})$ [13]. The peak potential of nicotine in this study was consistent with the value of metal-free carbon nanotube cluster-modified electrodes observed by Highton et al. [7].

Comparison of the CVs of modified and unmodified GCE showed that anodic current intensity increased sharply in the presence of the MWNTs and Cu NPs. In addition, oxidation of nicotine was catalyzed on the surface electrode, and the potential peak was shifted negatively. As can be seen in Fig. 1, the response to nicotine was clearly improved with a $\mathrm{Cu} \mathrm{NPs} / \mathrm{MWNTs} / \mathrm{GCE}$, indicating that GCE has been modified effectively by MWNTs and $\mathrm{Cu}$ NPs. The better performance of MWNTs/GCE compared with that of GCE may be due to nano-scale dimensions, electronic structure, and topological defects on the surface of the MWNTs [9, 21]. The CV of Cu NPs/MWNTs/GCE in absence nicotine (Fig. 1d) had no pick, confirming that the peak at $+0.75 \mathrm{~V}$ related to the oxidation of nicotine (Fig. 1c).

\section{Surface morphology of electrodes}

Figure 2a, b show the SEM image of the electrodes MWNTs/GCE and Cu NPs/MWNTs/GCE, respectively. As shown in Fig. 2b, Cu NPs were deposited in the form of compact spheres. They have formed homogeneous uniformly distributed nanoparticles on the surface electrode. Their average size was $90 \mathrm{~nm}$, which means that $\mathrm{Cu}$ NPs had surface characteristics such as high specific surface, high activity surface reaction, and effective transferring channels for analyte molecules to reach the active site, which helped to improve the sensitivity of the electrode.

\section{Investigation of experimental parameters}

Review of reports indicates that $\mathrm{pH}$, amount of modifier, concentration of MWNTs suspension, electro-deposition scan rate, number of cycles, and the concentration of $\mathrm{Cu} 2+$ cation are experimental parameters affecting the sensor response. According to the researchers' preliminary studies, the suitable amounts of modifier, number of cycles, and concentration of $\mathrm{Cu} 2+$ cation were obtained to be $10 \mu \mathrm{L}$, 20 , and $1.75 \mu \mathrm{mol} \mathrm{L}{ }^{-1}$, respectively. In the present study, the effect of $\mathrm{pH}$, concentration of MWNTs suspension, and electro-deposition scan rate were investigated as follows.

\section{Effect of $\mathrm{pH}$}

The electrochemical properties of nicotine have been considered as a function of $\mathrm{pH}$ [9]. So, its behavior on the
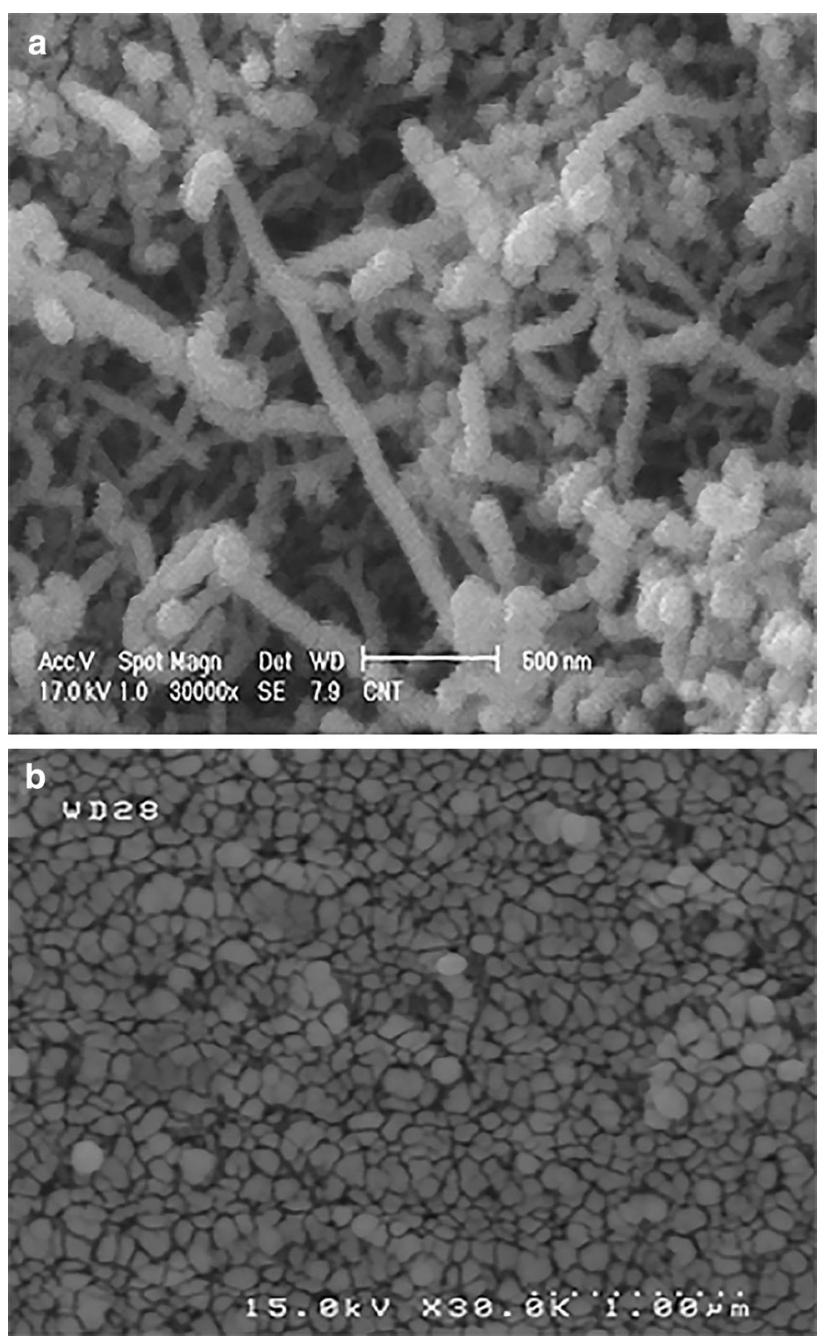

Fig. 2 SEM images of MWNTs/GCE (a) and Cu NPs/MWNTs/GCE (b)

MWNTs/GCE was studied by CV at different pHs. One of the most important electrochemical properties is its catalytic effect. To optimize it, the researchers recorded the voltammograms in the $\mathrm{pH}$ range of 6-10.

As shown in Fig. 3a, the modified electrode exhibited an electrocatalytic activity in response to the irreversible oxidation of nicotine in the $\mathrm{pH}$ range of 6-10. Maximum intensity of the peak current was at $\mathrm{pH}=7$. Therefore, this value was used as an optimum $\mathrm{pH}$ for all foregoing experiments.

Figure $3 \mathrm{~b}$ depicts values of the peak potential variation versus $\mathrm{pH}$. As can be seen, with increasing $\mathrm{pH}$ from acidic to basic, the peak potential was shifted toward the lower oxidation potential, indicating that protons were involved in the oxidation of nicotine.

As can be observed in Fig. 3, there is a linear relationship over the PH interval of $6-10$ that will deviate outside from this range. This may be due to the $\mathrm{pKa}$ values of 

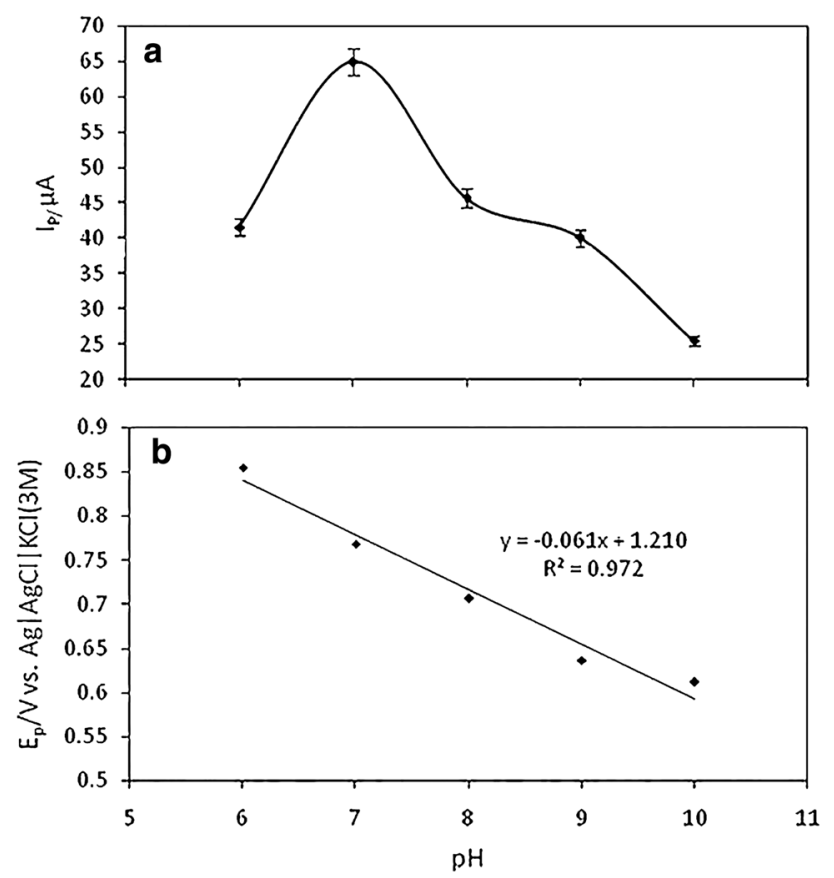

Fig. 3 Peak current (a) and peak potential (b) versus pH of $0.001 \mathrm{M}$ nicotine on MWNTs/GCE ( $1 \mathrm{mg} \mathrm{mL}^{-1}$ of MWNTs in DMF) with a scan rate of $50 \mathrm{mV} \mathrm{s}^{-1}$

groups' pyridine $\mathrm{n}$ pyrrolidine, the values of which were equal to 3.12 and 8.02 , respectively. Slope of this curve $(-61 \mathrm{mV} / \mathrm{pH})$ is close to the theoretical value $(-58.6 \mathrm{mV} /$ $\mathrm{pH})$, indicating that there were equal number of electrons and protons in the electrochemical oxidation of nicotine.

Effect of the concentration of MWNT suspension

The influence of MWNTs' concentration on the enhancement of electro catalytic oxidation of nicotine was evaluated. To optimize MWNT concentration, the researchers prepared four concentrations of MWNT suspension $(1.0,2.0,2.5,3.0 \mathrm{mg} / \mathrm{mL})$ in DMF solvent. Then, $10 \mu \mathrm{L}$ of each suspension was used for modifying GCE surface. After electrodepositing of $\mathrm{Cu}$ NPs on the surface electrodes by $\mathrm{CV}$, peak current response of $\mathrm{Cu} \mathrm{NPs} /$ MWNTs/GCE was determined in the presence of $0.001 \mathrm{M}$ nicotine in the phosphate buffer $(\mathrm{pH}$ 7.0) and scan rate of $50 \mathrm{mV} \mathrm{s}^{-1}$. As shown in Fig. 4, the oxidative peak current increased with increasing the concentration of MWNTs suspension in lower concentrations; while in higher concentrations, it declined with increasing concentration. This may be due to the increase in the numbers of active sites in the first region of the curve.

In the second region of the curve, however, the number of MWNT layers increased with increasing concentration, and the direct contact between the inner MWNTs and the analyte solution was weakened by further increasing the

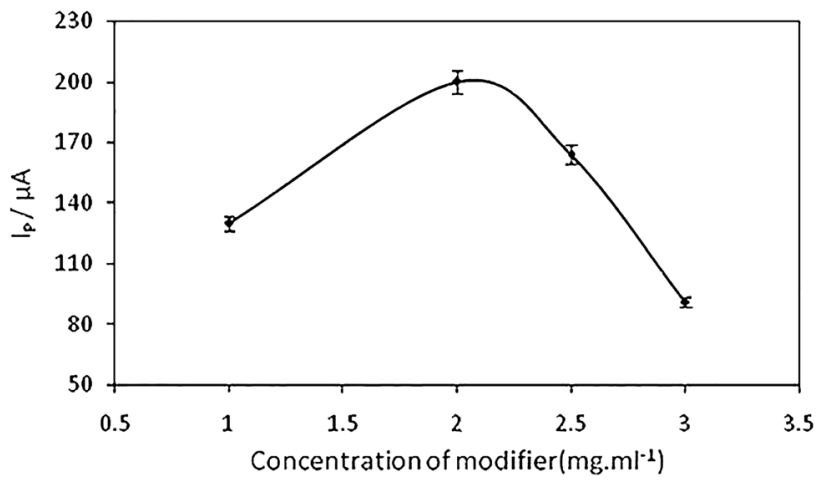

Fig. 4 Peak current response versus concentration of MWNT suspension of $\mathrm{Cu}$ NPs/MWNTs/GCE in the presence of $0.001 \mathrm{M}$ nicotine in the phosphate buffer $(\mathrm{pH} 7.0)$ with a scan rate of $50 \mathrm{mV} \mathrm{s}^{-1}$

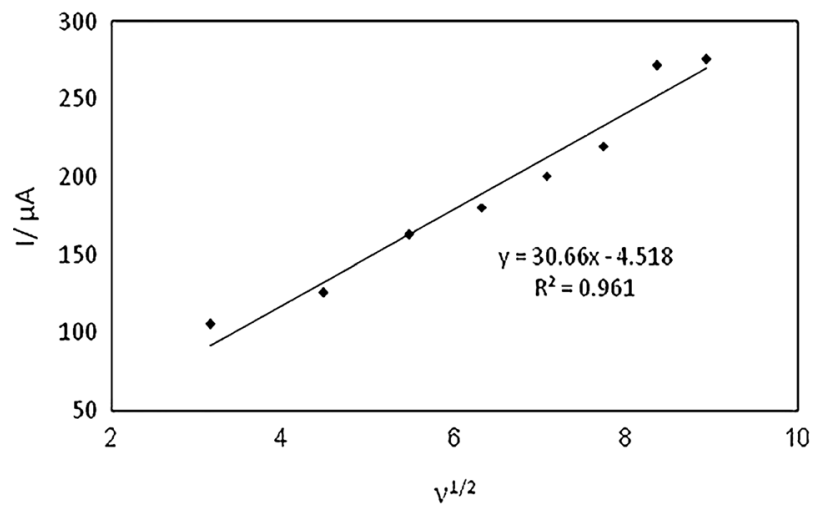

Fig. 5 Current response changes versus $v^{1 / 2}$ of $\mathrm{Cu}$ NPs/MWNTs/ GCE in the presence of $0.001 \mathrm{M}$ nicotine in the phosphate buffer $(\mathrm{pH}$ 7.0 ) at different scan rates from 10 to $80 \mathrm{mV} / \mathrm{s}$

concentration of MWNTs; the background current was increased and MWNTs were fallen down in the solution. The optimum concentration of MWNTs was revealed to be $2 \mathrm{mg} \mathrm{mL}^{-1}$.

\section{Effect of scan rate}

Effect of scan rate on the oxidation of nicotine on the surface of $\mathrm{Cu}$ NPs/MWNTs/GCE at different scan rates from 10 to $80 \mathrm{mV} / \mathrm{s}$ was, also, studied. With decreasing scan rate, no reduction peak was observed, which confirmed the irreversible oxidation of nicotine. There was a good linear relationship (Fig. 5) between the peak currents and square root of scan rates $\left(v^{1 / 2}\right)$, indicating that the oxidation of nicotine was controlled by a diffusion process.

Reproducibility and stability of the sensor

To demonstrate the accuracy and achievability of this proposed method for electro-deposition of $\mathrm{Cu}$ NPs, the 


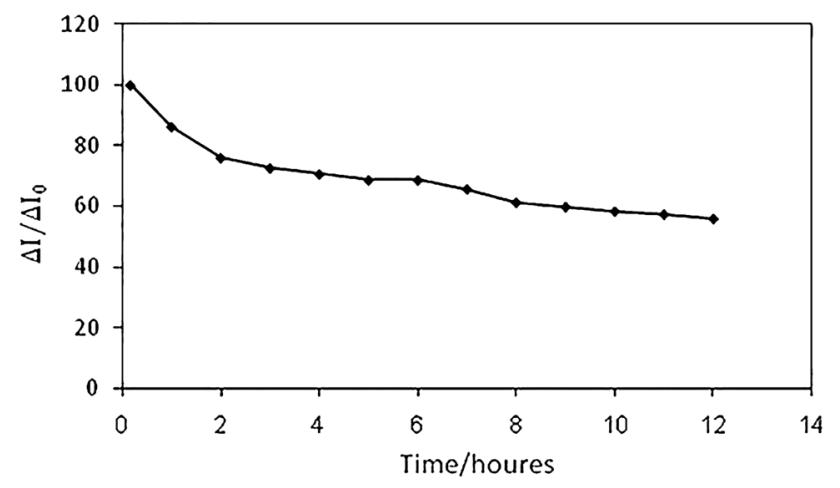

Fig. 6 Changes of $\Delta I / \Delta I 0$ versus time (h) in the presence of $0.001 \mathrm{M}$ nicotine in the phosphate buffer $(\mathrm{pH} 7.0)$ with a scan rate of $50 \mathrm{mV} \mathrm{s}^{-1}$

researchers studied the reproducibility and stability of the sensor. Reproducibility is one of the main principles of the scientific method. For this purpose, six series of successive measurements of $0.001 \mathrm{M}$ nicotine were done in $0.1 \mathrm{M}$ phosphate buffer. A good reproducibility electrode was achieved with a relative standard deviation of $5.68 \%$.

Electrode stability was studied under the conditions of $25^{\circ} \mathrm{C}, \mathrm{pH}=7.0$ and using $0.1 \mathrm{M}$ phosphate buffer containing $0.001 \mathrm{mM}$ nicotine. The sensor was stored in $0.1 \mathrm{M}$ phosphate buffer, and examined once an hour (Fig. 6). In Fig. $6, \Delta I$ is the difference of electrode current after storage. As can be seen, there is $14 \%$ loss of initial response within $1 \mathrm{~h}$. After $10 \mathrm{~h}$, the response current retained $60 \%$ of its initial response. The decrease in response may be due to the reduced activity of $\mathrm{Cu}$ NPs or nicotine deposits on the electrode surface.

\section{Calibration curve}

Since the peak current depends on the concentration of nicotine, CV method was used for drawing the calibration curve. Figure 7 is a plot showing that how the current responses of MWNTs/GCE and $\mathrm{Cu}$ NPs/MWNTs/GCE change with the concentration of nicotine, at optimum conditions. For MWNTs/GCE, it is linear in the concentration range of $1 \times 10^{-6}-9 \times 10^{-5} \mathrm{M}$ with equation of ip $(\mu \mathrm{A})=0.646 \mathrm{C}(\mu \mathrm{M})+22.70$ and a correlation coefficient of 0.966. And, it is also linear in the concentration range of $1 \times 10^{-4}-1 \times 10^{-3} \mathrm{M}$ with equation of ip $(\mu \mathrm{A})=$ $0.093 \mathrm{C}(\mu \mathrm{M})+74.31$, a correlation coefficient of 0.976 , and detection limit (LOD) of $1 \mu \mathrm{M}$.

For $\mathrm{Cu}$ NPs/MWNT/GCE, steady-state currents showed two linear relationships with the concentration in the range from $1-90$ to $100-1000 \mu \mathrm{M}$. Linear dependence of nicotine concentration was shown with regression equation of ip $(\mu \mathrm{A})=1.121 \mathrm{C}(\mu \mathrm{M})+16.00$, and correlation coefficient of 0.982 . It was also shown in another range with regression equation of ip

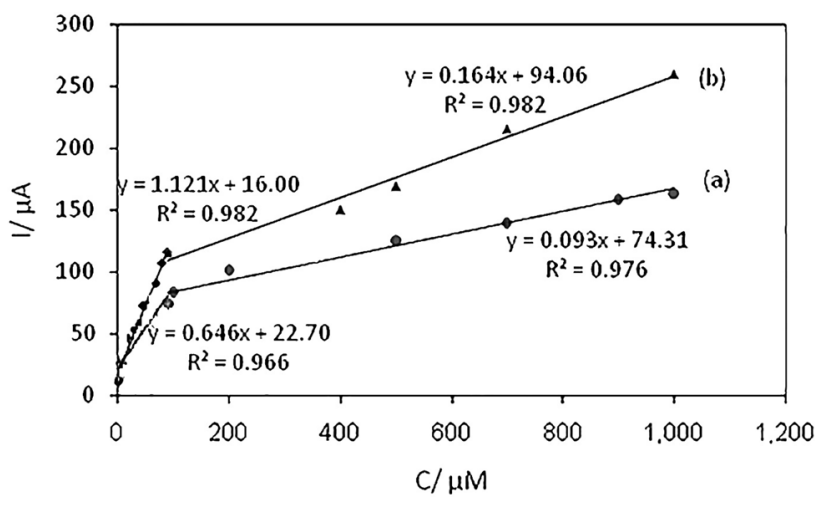

Fig. 7 Linear calibration curve of the peak current versus different nicotine concentration in the $0.1 \mathrm{M}$ phosphate buffer for MWNTs/ GCE (a) and $\mathrm{Cu}$ NPs/MWNTs/GCE $(b)$ at a scan rate of $50 \mathrm{mV} \mathrm{s}^{-1}$

$(\mu \mathrm{A})=0.164 \mathrm{C}(\mu \mathrm{M})+94.06$, correlation coefficient of 0.982 , and detection limit (LOD) of $1 \mu \mathrm{M}$.

\section{Conclusion}

This report described a novel, sensitive, and widely applicable detection method using copper nanoparticles $(\mathrm{Cu}$ NPs)/MWNTs/GCE. This modification with $\mathrm{Cu}$ NPs and MWNTs improved the sensitivity of the nicotine determination by reducing the over potential and increasing the current. Experimental parameters affecting the sensor response, such as $\mathrm{pH}$, concentration of MWNT suspension, electro-deposition scan rate, were studied and optimized at $7.0,2 \mathrm{mg} \mathrm{mL}^{-1}$, and $80 \mathrm{mV} \mathrm{s}^{-1}$, respectively. SEM images showed good dispersion of copper nanoparticles over CNT surface. The electrode exhibited a high catalytic activity toward the oxidation of nicotine with a slope calibration curve of $1.121 \mu \mathrm{A} / \mathrm{mM}$ in the range from $1 \times 10^{-6} \mathrm{M}$ to $9 \times 10^{-5} \mathrm{M}$ and another slope curve of 0.164 in the range from $1 \times 10^{-4}$ to $1 \times 10^{-3} \mathrm{M}$. The sensor displayed a good response to nicotine with a LOD of $1 \mu \mathrm{M}$. These results suggest that carbon nanotubes and copper nanoparticles are effective modifiers to enhance the sensitivity of glassy carbon electrode. It was observed that MWNTs and $\mathrm{Cu}$ NPs could facilitate the exchange of electrons with the electrode.

Open Access This article is distributed under the terms of the Creative Commons Attribution License which permits any use, distribution, and reproduction in any medium, provided the original author(s) and the source are credited.

\section{References}

1. Hengen, N., Hengen, M.: Gas-liquid chromatographic determination of nicotine and cotinine in plasma. Clin. Chem. 24, 50-53 (1978) 
2. Karaconji, I.B., Skender, L., Karacic, V.: Determination of nicotine and cotinine in urineby headspace solid phase microextraction gas chromatography with mass spectrometric detection. Acta. Chim. Slov. 54, 74-78 (2006)

3. Jacob, P., Benowitz, N.L., Yu, L., Shulgin, A.T.: Determination of nicotine $\mathrm{N}$-oxide by gas chromatography following thermal conversion to 2-methyl-6-(3-pyridyl)tetrahydro-1,2-oxazine. Anal. Chem. 58, 2218-2221 (1986)

4. Al-Tamrah, S.A.: Spectrophotometric determination of nicotine. Anal. Chim. Acta 379, 75-80 (1999)

5. Jung, J-h: Choo, J-b, Kim, D-J, Lee, S-H: Quantitative determination of nicotine in a PDMS microfluidic channel using surface enhanced Raman spectroscopy. Bull. Korean Chem. Soc. 27, 277-280 (2006)

6. Wang, S.-J., Liaw, H.-W., Tsai, Y.-C.: Low potential detection of nicotine at multiwalled carbon nanotube-alumina-coated silica nanocomposite. Electrochem. Commun. 11, 733-735 (2009)

7. Highton, L., Kadara, R.O., Jenkinson, N., Logan Riehl, B., Banks, C.E.: Metallic free carbon nanotube cluster modified screen printed electrodes for the sensing of nicotine in artificial saliva. Electroanal. 21, 2387-2389 (2009)

8. Suffredini, H.B., Santos, M.C., De Souza, D., Codognoto, L., Homem-de-Mello, P., Honório, K.M., da Silva, A.B.F., Machado, S.A.S., Avaca, L.A.: Electrochemical behavior of nicotine studied by voltammetric techniques at boron-doped diamond electrodes. Anal. Lett. 38, 1587-1599 (2005)

9. Xiong, H., Zhao, Y., Liu, P., Zhang, X., Wang, S.: Electrochemical properties and the determination of nicotine at a multiwalled carbon nanotubes modified glassy carbon electrode. Microchim. Acta 168, 31-36 (2010)

10. Escobar, S., Bernal, C., Mesa, M.: Kinetic study of the colloidal and enzymatic stability of $\beta$-galactosidase, for designing its encapsulation route through sol-gel route assisted by Triton X-100 surfactant. Biochem. Eng. J. 75, 32-38 (2013)

11. Xiao, Y., Zhang, X., Zhu, M., Tan, W.: Effect of the culture media optimization, $\mathrm{pH}$ and temperature on the biohydrogen production and the hydrogenase activities by Klebsiella pneumoniae ECU-15. Bioresour. Technol. 137, 9-17 (2013)

12. Zhang, B., Zhang, J., Yang, Q., Feng, C., Zhu, Y., Ye, Z., Ni, J.: Investigation and optimization of the novel UASB-MFC integrated system for sulfate removal and bioelectricity generation using the response surface methodology (RSM). Bioresour. Technol. 124, 1-7 (2012)

13. Levent, A., Yardim, Y., Senturk, Z.: Voltammetric behavior of nicotine at pencil graphite electrode and its enhancement determination in the presence of anionic surfactant. Electrochim. Acta 55, 190-195 (2009)

14. Wu, C.T., Chen, P.Y., Chen, J.G., Suryanarayanan, V., Ho, K.C.: Detection of nicotine based on molecularly imprinted TiO2modified electrodes. Anal. Chim. Acta 633, 119-126 (2009)
15. Ebrahimi, B., Shojaosadati, S.A., Ranaie, S.O., Mousavi, S.M.: Optimization and evaluation of acetylcholine esterase immobilization on ceramic packing using response surface methodology. Process. Biochem. 45, 81-87 (2010)

16. Parsajoo, C., Kauffmann, J.M.: Development of an acetylcholinesterase immobilized flow through amperometric detector based on thiocholine detection at a silver electrode. Talanta. 109, 116-120 (2013)

17. Male, K.B., Hrapovic, S., Liu, Y., Wang, D., Luong, J.H.T.: Electrochemical detection of carbohydrates using copper nanoparticles and carbon nanotubes. Anal. Chim. Acta. 516, 35-41 (2004)

18. Wang, Y., Wei, W., Zeng, J., Liu, X., Zeng, X.: Fabrication of a copper nanoparticle/chitosan/carbon nanotube-modified glassy carbon electrode for electrochemical sensing of hydrogen peroxide and glucose. Microchim. Acta. 160, 253-260 (2008)

19. Dai, X., Compton, R.G.: Gold nanoparticle modified electrodes show a reduced interference by $\mathrm{Cu}$ (II) in the detection of $\mathrm{As}(\mathrm{III})$ using anodic stripping voltammetry. Electroanal. 17, 1325-1330 (2005)

20. Gao, R., Zheng, J.: Amine-terminated ionic liquid functionalized carbon nanotube-gold nanoparticles for investigating the direct electron transfer of glucose oxidase. Electrochem. Commun. 11, 608-611 (2009)

21. Lin, J., He, C., Zhang, L., Zhang, S.: Sensitive amperometric immunosensor for alpha-fetoprotein based on carbon nanotube/gold nanoparticle doped chitosan film. Anal. Biochem. 384, 130-135 (2009)

22. Wang, Y., Wei, W., Liu, X., Zeng, X.: Carbon nanotube/chitosan/gold nanoparticles-based glucose biosensor prepared by a layer-by-layer technique. Mater. Sci. Eng. C 29, 50-54 (2009)

23. Cui, S.K., Guo, D.J.: Highly dispersed Pt nanoparticles immobilized on 1,4-benzenediamine-modified multi-walled carbon nanotube for methanol oxidation. J. Colloid. Interf. Sci. 333, 300-303 (2009)

24. Pang, X., He, D., Luo, S., Cai, Q.: An amperometric glucose biosensor fabricated with Pt nanoparticle-decorated carbon nanotubes/TiO2 nanotube arrays composite. Sensor. Actuat. B-Chem. 137, 134-138 (2009)

25. Raoof, J.B., Ojani, R., Esfeden, S.A., Nadimi, S.R.: Fabrication of bimetallic $\mathrm{Cu} / \mathrm{Pt}$ nanoparticles modified glassy carbon electrode and its catalytic activity toward hydrogen evolution reaction. Int. J. Hydrogen. Energ. 35, 3937-3944 (2010)

26. Su, L., Jia, W., Zhang, L., Beacham, C., Zhang, H., Lei, Y.: Facile synthesis of a platinum nanoflower monolayer on a singlewalled carbon nanotube membrane and its application in glucose detection. J. Phys. Chem. C. 114, 18121-18125 (2010) 